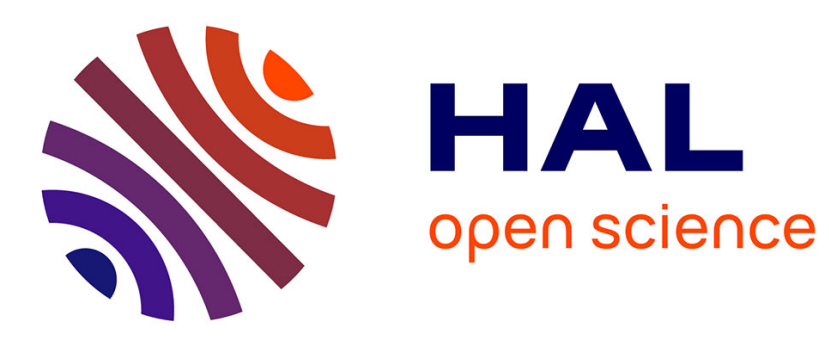

\title{
Space weather and risk management
}

H. Lappalainen, K. Kauristie, R. Pirjola

\section{- To cite this version:}

H. Lappalainen, K. Kauristie, R. Pirjola. Space weather and risk management. Advances in Geosciences, 2005, 3, pp.23-27. hal-00296789

\section{HAL Id: hal-00296789 \\ https://hal.science/hal-00296789}

Submitted on 16 Jun 2005

HAL is a multi-disciplinary open access archive for the deposit and dissemination of scientific research documents, whether they are published or not. The documents may come from teaching and research institutions in France or abroad, or from public or private research centers.
L'archive ouverte pluridisciplinaire HAL, est destinée au dépôt et à la diffusion de documents scientifiques de niveau recherche, publiés ou non, émanant des établissements d'enseignement et de recherche français ou étrangers, des laboratoires publics ou privés. 
Advances in Geosciences, 3, 23-27, 2005

SRef-ID: $1680-7359 /$ adgeo/2005-3-23

European Geosciences Union

(c) 2005 Author(s). This work is licensed

under a Creative Commons License.

\title{
Space weather and risk management
}

\author{
H. Lappalainen, K. Kauristie, and R. Pirjola \\ Finnish Meteorological Institute, Helsinki, Finland \\ Received: 18 August 2004 - Revised: 27 October 2004 - Accepted: 29 October 2004 - Published: 16 June 2005
}

\begin{abstract}
The term space weather is used for the solar driven variability in particle and electromagnetic conditions of the near-Earth space that may harm the performance of ground-based and space-borne technology. The European Union (EU) and the European Space Agency (ESA) have started a common programme called the Global Monitoring for Environment and Security (GMES). Many of the GMES operational services will rely on technology prone to space weather phenomena. For long-term environmental monitoring this is not a problem, but for applications of risk management in emergency situations the impact of space weather should be considered and evaluated. In this paper, we discuss how ESA's previous activity together with European national initiatives in the space weather area can be used to support GMES and how EU could participate in this work in its Framework Programmes and within the European Research Area (ERA).
\end{abstract}

\section{Introduction}

The term "Space weather" refers to particle and electromagnetic conditions in the Earth's space environment that may influence the performance of technological systems in space and on the ground (Office of the Federal Coordinator for Meteorological Services and Supporting Research, 1995). The Sun emits a continuous flow of charged particles to the surrounding space. The plasma system of these particles coupled with the solar magnetic field (interplanetary field) is called the solar wind. Space weather phenomena are associated with distinct structures in the solar wind, like bursts of high speed streams or shock fronts. These structures are caused by activations (flares) and certain structures (coronal holes) on the solar surface. The most intensive space weather storms are typically caused by coronal mass ejections (CME), i.e. plasma bubbles with scale sizes larger than the Earth's magnetosphere and with intrinsic conditions

Correspondence to: H. Lappalainen

(hanna.lappalainen@fmi.fi) differing significantly from the ambient solar wind plasma. Solar activity follows the eleven-year sunspot cycle, which means that occurrences of space weather storms also have a corresponding statistical variation. However, severe space storms can occur during sunspot minima as well.

The Earth's magnetosphere is that part of space where the geomagnetic field governs the plasma behaviour. Energy, momentum and mass transfers from the solar wind to the magnetosphere cause rapid variations in particle and electromagnetic conditions there. Variations in the inner magnetosphere, at the radiation belts, are crucial for geostationary monitoring of the Earth and communication technology. Some of the magnetospheric processes are coupled with the upper atmosphere, the ionosphere, and consequently drive significant variations e.g. in the ionospheric electric currents, which causes geomagnetic disturbances observable on the ground.

Space weather storms, better known as spectacular auroral displays among the general public, may damage and disturb the infrastructure of the society, e.g. risk management operations using optical data from Low Earth Orbiting (LEO) and Polar Earth Orbiting (PEO) satellites and meteorological data from geostationary satellites (GEO). During space weather storms the ionosphere gets heated and thickens. The consequent enhanced atmospheric drag complicates the attitude control of LEO and PEO satellites. Intensive variations in the radiation conditions cause anomalies in the geostationary satellite electronics. The global navigation satellite systems (GNSS, including in the future the US GPS and European GALILEO systems, http://europa.eu. int/comm/dgs/energy_transport/galileo) and telecommunication systems that are based on radio wave propagation (RFcommunication) also have crucial roles in several risk management applications. Space weather phenomena in the ionosphere can cause different problems in such systems (e.g. range errors and rapid phase and amplitude fluctuations, radio scintillations in satellite signals) that all lead to pronounced signal degradation causing problems to the system performance, accuracy and reliability. 


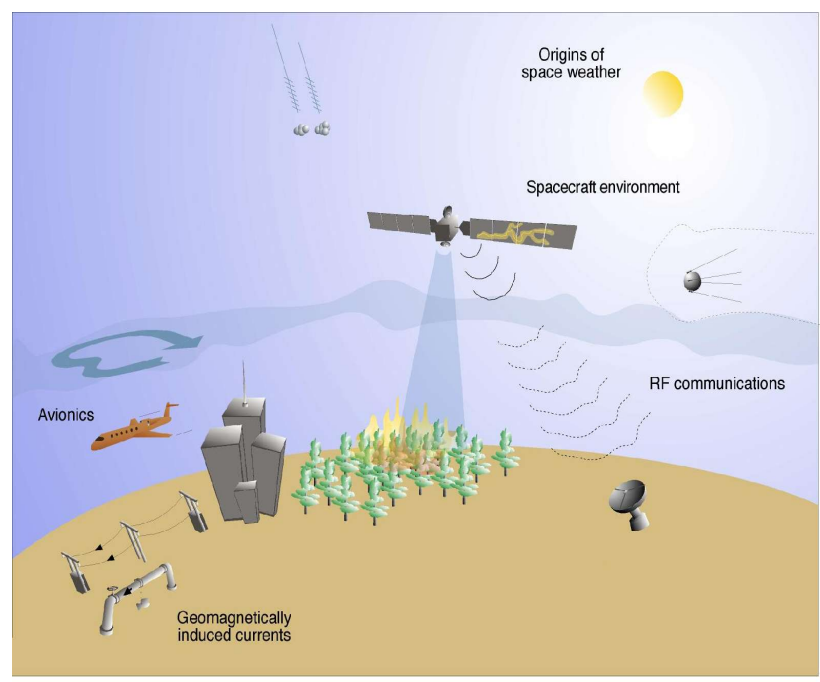

Fig. 1. Space weather phenomena and technological systems relevant for risk management and every-day life (Pirjola et al., 2003).

In addition to the infrastructural effects, space weather may also affect directly every-day life. For example, aviation utilizes several technological systems prone to space weather effects and anomalies in their operation are of immediate concern to the general public. Many of the innovations made in space weather research to mitigate space weather effects on satellite operations are beneficial for aviation applications as well. Solar activity governs also the amount of the unhealthy radiation effects that aircrew and frequent flyers experience.

Geomagnetically induced currents (GIC) in long manmade conductors are the most traditional space weather phenomenon. These ohmic currents are driven by the electric field associated with geomagnetic disturbances. GIC cause problems to power transmission systems and to oil and gas pipelines. The first documented GIC events took place in old telegraph systems in the 1850's (Boteler et al., 1998). The most severe GIC catastrophe took place in the Hydro-Quebec power network in Canada in March 1989 (Bolduc, 2002), when millions of customers had to cope without electricity for several hours. More recently in October 2003, a similar, although smaller, blackout occurred in southern Sweden. More detailed descriptions about GIC and other space weather effects can be found e.g. from the review articles by Jansen et al. (2000), Koskinen et al. (2001) and Jansen and Pirjola (2004) and references therein.

Various space weather phenomena are summarized in Fig. 1.

\section{Space weather and risk management}

With the increasing use of satellite systems in the modern European society the need of improved services in space weather monitoring and forecasting is obviously becoming crucial. Especially, the need for a continuously operating reliable European space weather service to support natural hazard monitoring and risk management operations should be evaluated. The evaluation and the service development should be made in close collaboration with motivated user groups such as the aerospace industry, airlines, electric power companies, teleoperators, researchers and general public. In the USA the Space Environment Centre of the National Oceanic and Atmospheric Association (NOAA/SEC) takes care of the systematic space weather monitoring. In Europe there are several on-going national monitoring programmes, but a NOAA/SEC-type institution coordinating and collecting the outcome of the national efforts is still under development.

Space-borne monitoring systems at LEO, PEO and GEO orbits and satellite and ground-based telecommunication networks will play key roles in future risk management operations. For example, systems monitoring the potential risk of forest fires will take advantage of geostationary meteorological observations when predicting the evolution of thunderstorm fronts. In the crisis management of severe accidents GPS services will be used to coordinate the movements of the rescue teams. In such cases it is important that the environmental observations or the position data are correct and available with refreshment rates of a few minutes. Consequently, although the probability for a severe accident to take place during a strong space weather storm is small we should gather more quantitative information about the reliability of the transmitted data and about the available backup systems in the special conditions.

\section{Risk management and the GMES programme}

The risk monitoring services along with eleven other satellite-based environmental application fields are under development in the programme called the Global Monitoring for Environment and Security (GMES). GMES is a joint undertaking by the European Union (EU) and the European Space Agency (ESA). The risk management is concentrated on environmental areas relevant for the security of European citizens such as floods, forest fires, oil spills, landslides and stability of man-made structures. Many of the GMES services are, to a large extent, planned to be based on spaceborne remote sensing instrumentation and on communication links to the ground. The GMES infrastructure and operational services are intended to be operational by the year 2008 after having the initial period (2001-2003) followed by the implementation period (2004-2007).

During the initial period nine potential candidate projects demonstrated operational services funded by EU, ESA and national funding institutions. At the end of the initial period there finally will be a selection of GMES services for the final infrastructure, which most probably will include one segment for risk management. Many of the phenomena to be monitored by this service are slowly-evolving, like migration of the coastal lines, but the service should also address rapidlyevolving natural and technological hazards, which implies 
operations prone to space weather disturbances as described above.

On the ESA side, the GMES funding is distributed within the GMES Service Element (GSE) programme. GSE started with a consolidation phase, which according to the original plan will be followed by a selection of a few full-fledged services starting operation in 2004. One of the GSE projects is RISK-EOS (http://www.risk-eos.com/) which will use data from the EUMETNET (http://www.eumetnet.eu.org/) monitoring system (ground-based, airborne, and marine instrumentation) for the prevention, early warning, and crisis and post-crisis management of floods and forest fires.

On the EU side, the funding for risk-management-related research and product development is distributed e.g. in context of the 6th Framework Programme under the Aeronautics and Space priority. EU has published calls for risk management Integrated Projects (IP) and for smaller Specific Targeted Research Projects (STREP). An European consortium led by the Finnish Meteorological Institute has actively tried to fit and scope a space weather service into the GMES context and has submitted STREP-type proposals for two EUFP6-GMES-calls issued in the springs of 2003 and 2004. The latter proposal followed the above-described GMES philosophy and identified the general goals towards a coordinated European space weather service infrastructure as a whole. Unfortunately neither of the proposals was considered mature enough for the GMES and risk management context.

\section{COST and ERA activities}

European Communities have belonged to the foundation parties of the European Cooperation in the field of Scientific and Technical Research (COST) that was set up more than 30 years ago. Since those days COST has catalyzed European collaboration in different research areas by supporting and funding networking, conferences, short-term scientific exchanges and publications. Recently European Communities have started common arrangements to establish the European Research Area (ERA) to search and enhance synergy between national research activities. The COST activities are anticipated to make a strong contribution to the ERA progress in the future (Fedi, 2004). From the viewpoint of space weather research and product development, these are good news, since a new four-year COST program, "Developing the scientific basis for monitoring, modelling and predicting space weather" (COST 724), started in November 2003 to support space-weather-related research and to explore methods for providing coordinated European space weather services (Lilensten et al., 2004). COST 724 will be one of the most important coordinating parties when establishing the practice of the European Space Weather Weeks and a European NOAA/SEC-type space weather centre. COST 724 will also increase the public awareness of space weather phenomena affecting our every day life by having separate outreach actions, e.g. web pages.

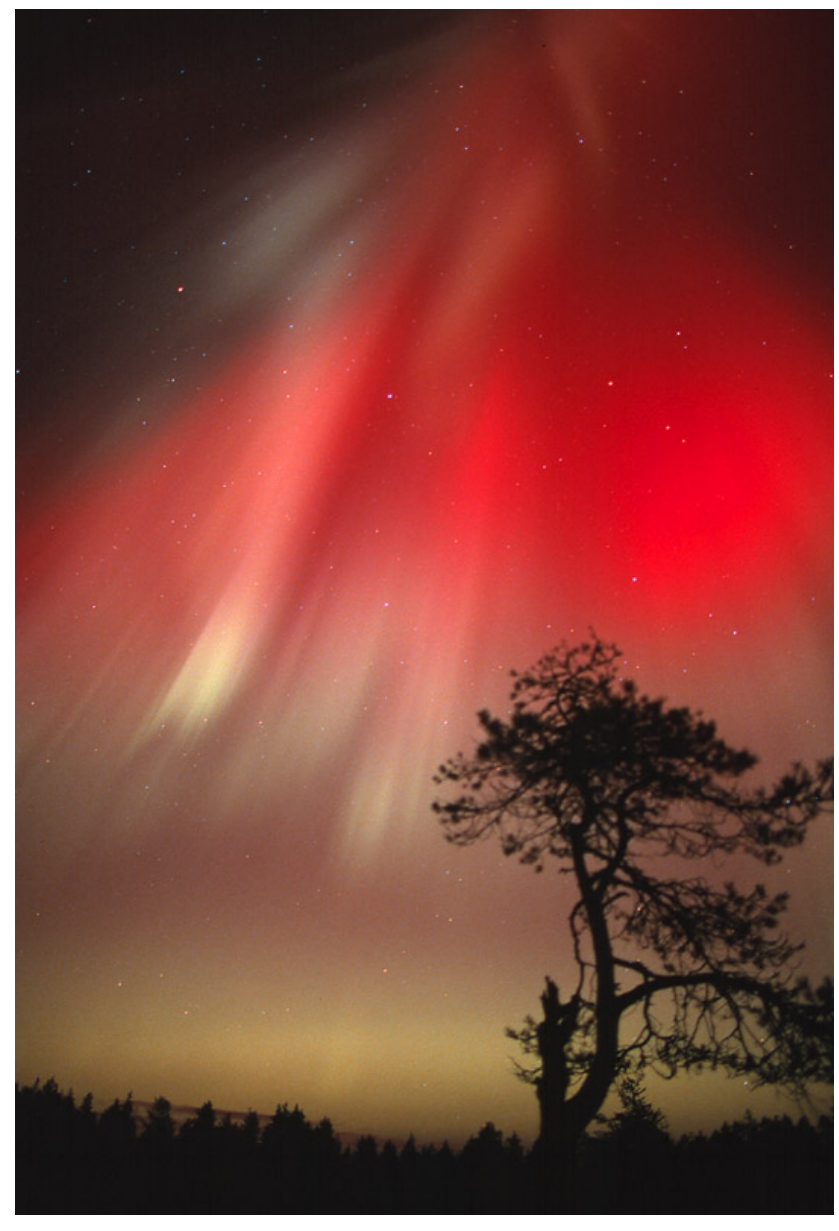

Fig. 2. Auroras in Northern Finland, 21.10.2001 (Photo by J. Jussila).

\section{ESA space weather activities}

ESA has taken an active coordinator role in the development of operational European space weather services. After conducting two studies on the importance of space weather effects for the European society, ESA started a Space Weather Pilot Project funding 17 Service Development Activities (SDAs) in 2003 (http://www.esa-spaceweather.net). The Pilot Project implies the development of space weather services which are defined and developed by the ESA pilot project contractors with the support by specific end user groups. After evaluation of their usefulness and cost/benefits the SWENET (Space Weather European Network) infrastructure will be established in 2005. SWENET will include the public parts of the software developed within the SDAs and a partial replica of the NOAA/SEC data server.

The SDAs include several initiatives that will also be beneficial for the GMES risk management activities. For example, GEISHA (Geosynchronous Environment for Identification of Satellite Hit Anomalies) and SWIPPA (Space Weather Impact on Precise Positioning Applications of GNSS) will build data assimilation tools that help mitigate space weather disturbances in geostationary and GPS operations. Both 


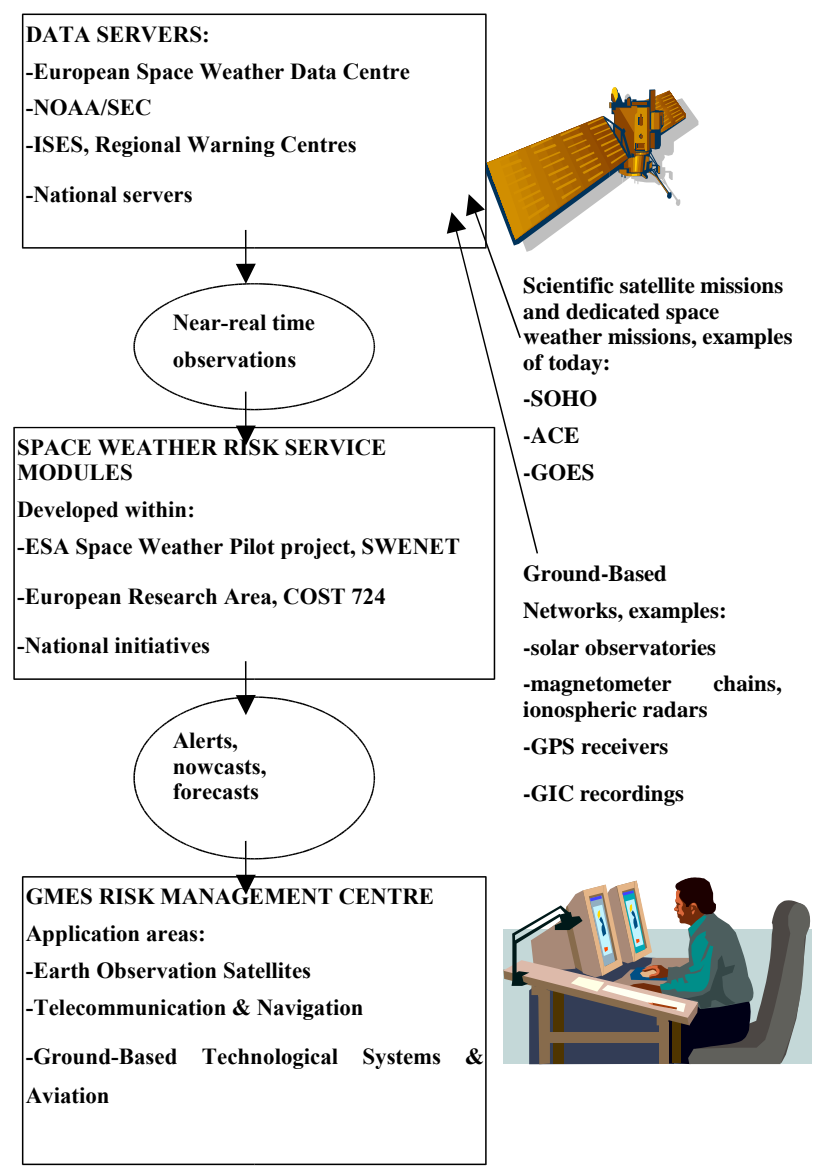

Fig. 3. A suggestion for ESA-EU collaboration for a coordinated space weather monitoring system to support the future GMES risk management centre. For the satellite missions SOHO, ACE and GOES find more information from http://www-istp.gsfc.nasa.gov/ istp/. ISES stands for International Space Environment Service (http://ises-spaceweather.org/).

efforts will use state-of-art theoretical models from solarterrestrial research and near real-time observations from ground-based and satellite instruments to perform the nowcasting and forecasting. SOARS (Space weather Operational Airline Risk Service) will develop a simulation of the different space weather impacts on a virtual airline and a prototype for an airline space weather service. SIDC (Solar Influences Data Centre) is an Internet-based system monitoring solar activity and generating emails or SMS alerts for interested customers.

Auroras provide a nice setting to educate the general public about space weather. Thus ESA has also included a public outreach aspect in the SW pilot project. One of the SDA's, called "Auroras Now", is targeted to the general public only and it will help indentify the best timing to see auroras (Fig. 2). This service currently maintained by the Finnish Meteorological Institute (http://aurora.fmi.fi/public_service/) is based on magnetometer and allsky-camera data measured in Southern (Nurmijärvi Observatory 60.50 N, 24.65 E) and Northern Finland (Sodankylä Observatory 67.37 N, 26.63 E).
For more detailed education suitable e.g. for secondary school and upper elementary school students EU has supported the development of space weather CD-roms in several different languages. In the higher level education space weather matters could provide a relevant topic for joint teaching programmes for technical universities (the engineering aspect) and traditional universities (the geophysics aspect).

\section{Future prospects}

The ESA-EU GMES programme provides a good reason to sharpen European space weather activities. ESA's SWENET and COST 724 within the ERA framework are concrete efforts towards a unified and coordinated European space weather service. While COST 724 is more research-oriented SWENET has tight links with the customers and tailored data products. Thus, there already exist a basis for space weather development and research groups which were suggested in ESA's original implementation plan for a European space weather programme (Hapgood, 2001). Although the collaboration between scientists and engineers is not always fluent both communities are necessary in the space weather area: a service cannot be useful without detailed specifications of customer needs and the predictions cannot be improved without profound solar-terrestrial research programmes.

GMES risk management applications will be dependent on the services by commercial satellite designers, operators and launchers who are not willing to distribute any information about anomalous situations in their systems. Error events can be analysed practically only from records of scientific satellites, which are freely available for the whole research community. Some of the national space agencies collect more comprehensive lists, but for limited access only. One of the major objectives for the future European space weather service is to initiate another way of working, i.e. to have access to confidential data bases, to keep confidentiality during the analyses, and finally to produce results in terms of recommendations, norms and thresholds which may be widely distributed to European authorities, industry and research community. When the GMES risk management applications will be up and routinely operated it will be easier for the space weather community to collaborate with the service developers and users in order to probe the probable pitfalls that space weather can cause in the monitoring procedures.

Space weather forecasts are not possible without nearreal time data. So far NOAA/SEC has been the primary data pool that is also widely used by several European space weather applications. Within SWENET the US service will be complemented by European observations. Ground-based instrument networks are maintained mainly as national programmes while ESA has the primary coordinator role in the design and building of instruments for the more expensive satellite missions. So far ESA has funded mainly researchoriented missions, but in the future a space-borne monitor dedicated especially to space weather applications or space weather instruments as hitch-hikers onboard other satellites 
may become actual, either with ESA funding or as a collaboration effort between national institutes.

Despite of the failures in the recent EU bids the concept of a tailored space weather segment integrated to a GMES risk management centre may still become relevant later when the risk monitoring systems will be fully operational. Figure 3 illustrates a suggestion for such a service and lists some current activities which could participate in the initiative. The future need for space weather forecasts is mentioned in "An action plan for implementing the European Space policy" a Commission document called White Paper (Commission of the European Communities, 2003). In the EU the global monitoring and a large part of the observation requirements stemming from security and defense needs are suggested to be fulfilled through the GMES undertaking. It is interesting to note that in USA the military forces conduct space weather research, maintain their own operational monitoring centre, and collaborate closely with NOAA/SEC.

According to the White Paper, in order to build up a comprehensive long-term EU space-based security capability, Europe will also need developments of systems and services e.g. in the fields of monitoring electromagnetic activities and space surveillance allowing the EU an autonomous capacity to detect and identify space objects. Space weather can be a relevant issue for these applications both as a disturbance that must be eliminated and as a research area that may generate useful innovations. However, the time of concrete actions is in the future since the Commission anticipates still detailed evaluation of the capabilities and role of space policy in support of European defence and security.

Acknowledgements. The authors would like to thank the many European colleagues who have participated in common efforts to introduce space weather into EU-FP6. J. Jussila is acknowledged for providing the auroral photo.

Edited by: V. Rosmorduc

Reviewed by: J. Kunches and V. Rosmorduc

\section{References}

Bolduc, L.: GIC observations and studies in the Hydro-Québec power system, Journal of Atmospheric and Solar-Terrestrial Physics, 64, 16, 1793-1802, 2002.

Boteler, D. H., Pirjola, R. J., and Nevanlinna, H.: The effects of geomagnetic disturbances on electrical systems at the earth's surface, Advances in Space Research, 22, 1, 17-27, 1998.

Commission of the European communities: Space: a new European frontier for an expanding Union, an action plan for implementing the European Space policy, White paper, $\operatorname{COM(2003)~673,~}$ Brussels, 11 November 2003.

Fedi, F.: View from the Top: COST is lighting the way to a bottomup ERA in Framework 7, Research Europe, 1, July 2004.

Hapgood, M.: ESA Space Weather Study (ESWS): Project Implementation Plan and Final report, ESWS-RAL-RP_0002, Issue 0.9, November 2001, 78 pp., 2001.

Jansen, F. and Pirjola, R.: Space weather research elucidates risks to technological infrastructure, EOS Transactions American Geophysical Union, 85, 25, pp. 241, 245-246, 2004.

Jansen, F., Pirjola, R., and Favre, R.: Space weather, Hazard to the Earth? Swiss Re Publishing, Swiss Reinsurance Company, Zurich, Switzerland, R\&R, 6/00, 4000 en, 40 pp., 2000.

Koskinen, H., Tanskanen, E., Pirjola, R., Pulkkinen, A., Dyer, C., Rodgers, D., Cannon, P., Mandeville, J.-C., and Boscher, D.: Rationale for a European Space Weather Programme, Finnish Meteorological Institute Reports, 2, 53 pp., 2001.

Lilensten, J., Clark, T., and Belehaki, A.: Europe's First Space Weather Think Tank, Space Weather, 2, S04001, doi:10.1029/2003SW000021, 2004.

Office of the Federal Coordinator for Meteorological Services and Supporting Research: The National Space Weather Program, The Strategic Plan., FCM-P30-1995, Washington D.C., USA, August 1995, 18 pp., 1995.

Pirjola, R., Lappalainen, H., and Kauristie, K.: Space weather and risk management, Invited Paper for the " 54 th International Astronautical Congress", Bremen, Germany, 29 September-3 October 2003, 9 pp., 2003. 